\title{
Emergency and rehabilitation preparedness at a community level: the Montbéliard experience
}

\author{
C. CROTEAU ${ }^{1}$, P. BOITEUX ${ }^{2}$, C. BATAILLE ${ }^{1}$, P. CROÜAIL $^{1}$, J. LOCHARD $^{1}$, \\ I. NETILLARD ${ }^{2}$, W. RASKOB ${ }^{3}$
}

\begin{abstract}
The Montbéliard Community of Municipalities (CAPM), located in the Eastern part of France, is facing different types of natural and technological risks that could affect its territory: flooding, chemical and radiological accidents, etc. In 2006, as part of its Radiation Protection Pilot Project, the CAPM decided to engage a specific collaboration with CEPN and KIT within the EURANOS Project to explore the preparedness process associated with potential nuclear or radiological emergencies and recovery situations. For this purpose, the RODOS Decision Support System for emergency and rehabilitation preparedness was used at a community level. After customisation of the tool with local data, different accident scenarios were simulated. As a result, the territory has engaged concrete actions (inventorying buildings that could accommodate populations in case of evacuation, assessing iodine tablets stocks available on the territory).
\end{abstract}

\section{Origin and objectives of the project}

In March 2004, the Montbéliard Community of Municipalities (CAPM), in cooperation with CEPN, initiated the Montbéliard Radiation Protection Pilot Project (Bulletin of the Nuclear Protection Evaluation Centre, 2008; Bataille et al., 2010). The main objectives of this Pilot Project are to improve the radiation protection of the inhabitants of the Montbéliard Community in the various exposure situations that they can potentially encounter on the territory (natural, medical and industrial) as well as to promote the creation of a centre of competence in the field of radiation protection in the Montbéliard area.

Since the beginning of the Pilot Project, the management of the potential consequences of a nuclear accident at the Fessenheim Nuclear Power Plant located 70 kilometres North East from the Montbéliard Community or of a transport accident involving radioactive material on the highway crossing the Community

\footnotetext{
1 Nuclear Protection Evaluation Centre (CEPN), 28 rue de la Redoute, 92260 Fontenay-aux-Roses, France.

2 Communauté d'Agglomération du Pays de Montbéliard (CAPM), 8 avenue des Alliés, BP 98407, 25208 Montbéliard Cedex, France.

3 Karlsruhe Institute of Technology (KIT), Hermann-von-Helmholtz-Platz 1, 76344 Eggenstein-Leopoldshafen, Germany.
} 
was considered as a relevant issue by the local actors. This led the CAPM to participate in the EURANOS Project with the objective to be familiarized with the challenges of nuclear and radiological emergencies and post-accident situations.

Responding to the French law of 13 August 2004 related to the modernization of civil security requiring the development of Local Community Emergency Plans in all municipalities, the CAPM decided to create a "Risk Assessment and Management Group" involving local actors to evaluate the opportunity and feasibility of developing preparedness actions in case of emergencies. These were considered in a multiple risk perspective including flooding, chemical or bacteriological accidents and pandemics.

The developments within the "Risk Assessment and Management Group" and the EURANOS Project led the CAPM to create in 2006 a specific action on "Radiological Risk Management" as part of the Radiation Protection Pilot Project with the objective to explore what could be the consequences of particular nuclear and radiological accidents on the Montbéliard territory.

In order to facilitate and support this action, the CAPM, CEPN and KIT decided to launch a new R\&D activity (CAT3RTD02) within the EURANOS Project and to use the RODOS (Realtime Online DecisiOn Support system for nuclear emergency management) Decision Support System to:

- explore the potential consequences of different scenarios of nuclear or radiological accidents that could affect the Montbéliard Community,

- understand the problems at stake in case of such events and evaluate the vulnerability of the territory,

- identify the countermeasures that would have to be implemented and engage a reflection on accident and post-accident preparedness at the community level.

\section{Results obtained}

After the acquisition of RODOS (Müller et al., 2010) by the CAPM, the first step of the work consisted in gathering and customising the relevant local data (population, elevation, types of soils and land use, foodstuffs...) to feed the RODOS Geographic Information System.

Then, two types of scenario were simulated:

- Nuclear Power Plant accidents. Although no nuclear power plant is located in the Montbéliard territory, several French and Swiss reactors are situated in a less than 100 kilometres radius and a serious accident at one of these reactors could potentially affect the territory. Only accident scenarios at the Fessenheim NPP located 70 kilometres North East from the Montbéliard territory have 


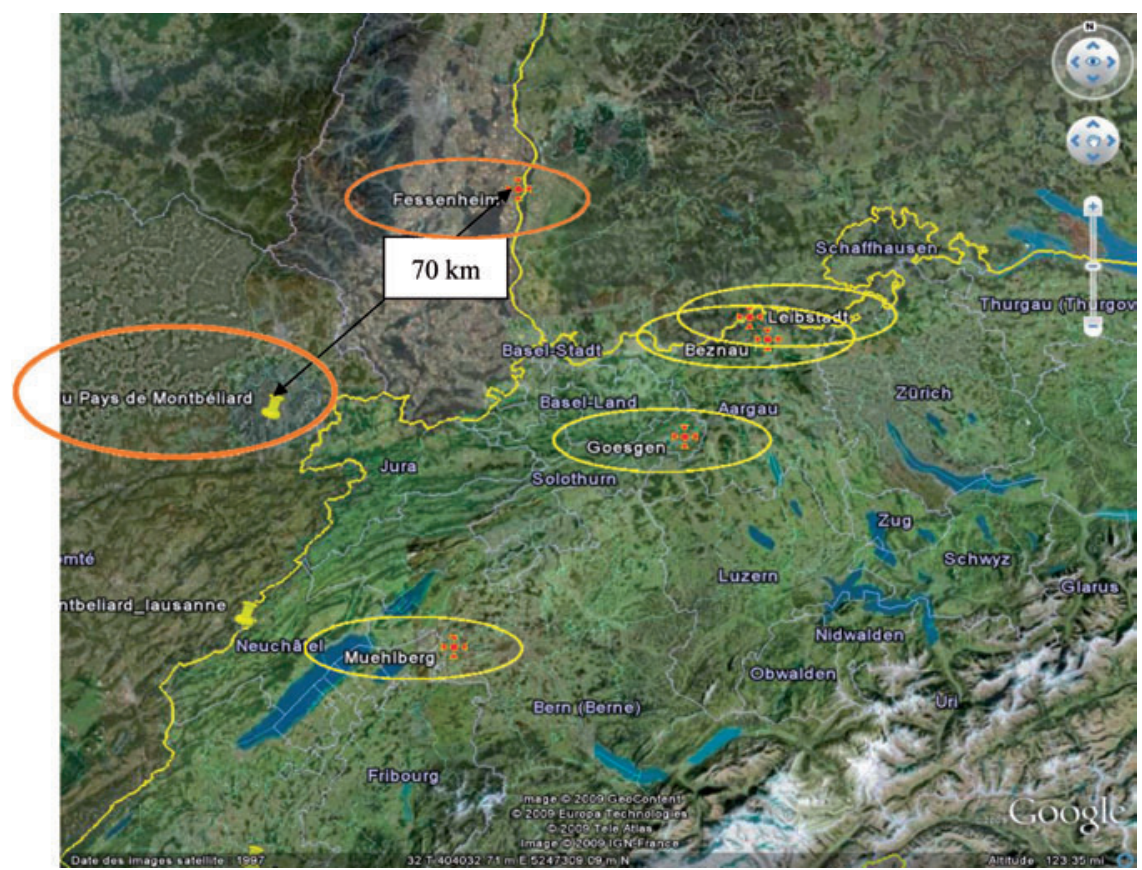

Figure 1 - Location of the Montbéliard Country and the Fessenheim NPP.

been considered (Fig. 1). Having difficulties to obtain appropriate source-terms for French NPP accidents, two source-terms from the RODOS library were finally used.

O The first one coming from the INEX 1 (INEX 1, 1995) exercise consisting in a liquid leak in the primary circuit (only the phase 1 of INEX1 has been considered).

O The second one comes from a German risk study (Gesellschaft für Reaktorsicherheit, 1981). It consists in a steam generator tube leak (bypassing the containment via the primary system). This scenario was discussed with nuclear safety experts of the French Institute of Radiation Protection and Nuclear Safety (IRSN). They pointed out that this scenario is not appropriate because of the specific filters installed in the stack of French reactors that allow to reduce the aerosol releases in case of such an accident. Consequently, the global source-term is not relevant for a French NPP (PWR). For the sake of the simulation a total failure of the filters was assumed keeping in mind that the scenario was a rather improbable sequence but was allowing to consider the worst imaginable consequences on the CAPM. 


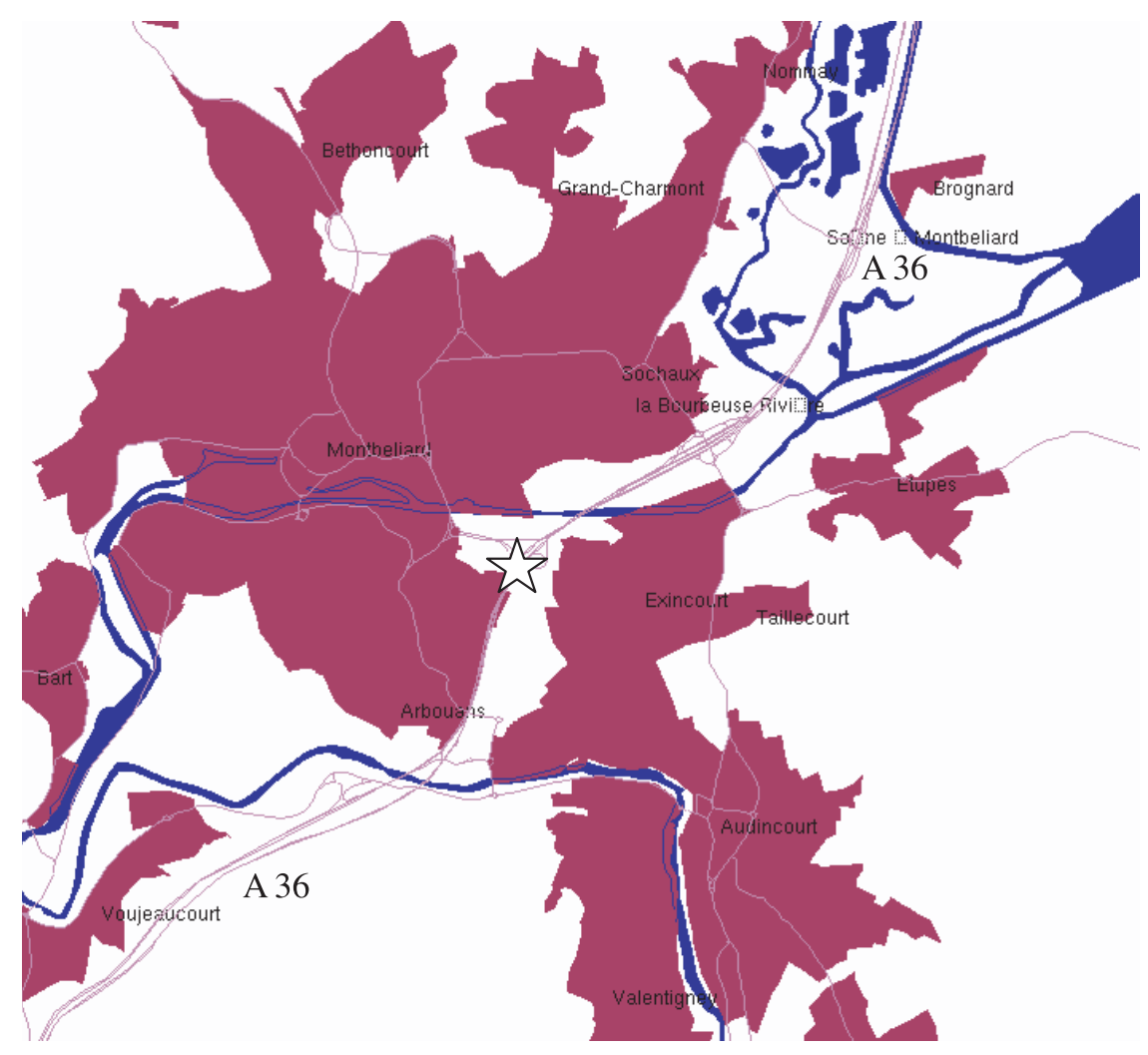

Figure 2 - Location of the transport accident in RODOS ( $\vec{\zeta}$ ).

- Transport accidents. An important freeway (A36 joining the South and the North of Europe through the Rhine-Rhone route) crosses the Montbéliard territory and is regularly used to transport radioactive materials (e.g. radioactive waste, industrial sealed or unsealed sources...). Furthermore, the Montbéliard hospital includes services of nuclear medicine and therefore many radioactive sources are transported locally. It was decided to simulate a transport accident on the A36 freeway (Fig. 2) at a place known as a dangerous one where many road accidents already occurred. The considered carrier was a truck transporting a source of caesium-137.

The RODOS tool allowed a first assessment of the radiological consequences as well as the type of countermeasures associated with the selected scenarios. In case of a medium sized accident at the Fessenheim NPP (first source-term), the territory 
would have to implement foodstuffs restrictions on some products (e.g. milk, leafy vegetables) during limited periods of time. In case of a severe accident (second source-term), emergency countermeasures would have to be considered. This would comprise sheltering and distribution of iodine tablets An accident of a truck transporting a caesium-137 source would result in only very local consequences, mainly in the nearest agricultural areas and rivers. Emergency actions would not be necessary.

Building on these results, the Montbéliard local actors engaged some practical actions to be better prepared in case of a radiological event. First, the buildings that could accommodate populations in case of an evacuation have been identified. Their location and characteristics have been captured into the Geographic Information System (GIS) of the Montbéliard territory. Secondly, an inventory of the stocks of iodine tablets, available on the territory, has been made.

On April 2009, the new version of RODOS (JRODOS) which allows to easily import and export GIS files has been installed at the CAPM (Trybushnyi et al., 2010). The results of the scenarios estimated with JRODOS were then exported in the CAPM GIS. Such an approach greatly facilitated the understanding of what is at stake in the territory in case of an accident (vulnerable areas, identification of ways of improvement,...) and facilitated the dialogue with the local authorities and professionals.

This preparedness process initiated within the EURANOS Project is still going on. The CAPM is further exploring the potential of linking the tools developed and tested within the Project with the Community Geographic Information System. In this perspective, the next step will be a simulation exercise with the MOIRA Decision Support System (Gallego et al., 2009) to identify the problems associated with the potential contamination of the regional water ecosystem.

\section{Conclusion}

The experience with RODOS in the Montbéliard territory demonstrated that users at a community level are not interested at the real-time feature of such a tool but highly appreciate its capabilities to simulate a large variety of scenarios allowing the local actors to better understand the possible consequences of potential nuclear or radiological events that could affect their territory. By linking the results of these simulations to the community GIS, the actors involved are in a position to identify concretely which type of actions they would have to implement in case of an emergency. In this perspective, the CAPM experience has demonstrated that RODOS is a powerful training tool for developing new competences at the local level for emergency and rehabilitation preparedness. 
However, the local users were confronted with several technical difficulties when implementing RODOS in its present state of development, such as:

- difficulties to understand all the nuclear and radiological protection vocabulary,

- difficulties to choose and collect the necessary data for the scenarios description: source-terms, meteorological conditions, dispersion parameters, etc.

- difficulties to interpret the numerous results generated by the software.

Mastering the tool was also a long process that required a technical facilitation from KIT and CEPN.

The two remarks above led to conclude that tools such as RODOS that were initially developed to support the decision making process during an emergency are still difficult to be applied by local users wishing to engage their territories in an emergency and recovery preparedness approach. Following these conclusions, KIT, CEPN and the Montbéliard region, together with further interested local communities, consequently decided to create a Working Group to better understand the needs and expectations of local users, with the final objective to adapt the existing tools to the needs of the territories. The Working Group met already twice. It is expected that the activities of this Working Group will be developed in the future in the broader framework of the NERIS Platform (European Platform on Preparedness for Nuclear and Radiological Emergency Response and Recovery), that will allow to engage new local communities, test new tools and better address the key issues at stake for local communities engaged in emergency response and recovery preparedness.

\section{REFERENCES}

Bataille C., Schneider T., Lochard J. (2010) Retour d'expérience du Projet Pilote Radioprotection du Pays de Montbéliard (2004-2009), CEPN Report 310.

Bulletin of the Nuclear Protection Evaluation Centre (2008) Special report: the CAPM Radiation Protection Pilot Project, Risk \& Prevention.

Gallego E., Magán M., Cadierno J.P.G., Gil E., Monte L., Hofman D. (2009) Long-term management of contaminated freshwater bodies and catchments. Decision making exercise with the MOIRA system, Radioprotection 44, 683-688.

Gesellschaft fur Reaktorsicherheit: Deutsche Risikostudie Kernkraftwerke. Fachband 8, Unfallfolgerechnungen und Risikoergebnisse. Verlag TuV Rheinland, ISBN 3-88585-019-2 (1981).

Ievdin I., Trybushnyi D., Zheleznyak M., Raskob W. (2010) RODOS re-engineering, Radioprotection 45, S181-S189.

INEX 1 - An International Nuclear Emergency Exercise, OECD (1995), ISBN 92-64-14560.

Müller T.O., Raskob W., Vaziri Elahi S. (2010) User friendly application of RODOS, Radioprotection 45, S171-S179. 